\title{
Trends in influenza vaccination behaviours - results from the CoPanFlu cohort, France, 2006 to 2011
}

A L Caille-Brillet (alcailleb@gmail.com)1,2, J Raude ${ }^{1,2}$, N Lapidus ${ }^{3,4}$, X De Lamballerie ${ }^{2}$, F Carrat ${ }^{3,5}$, M Setbon $^{1,2,6}$

1. Department of Social and Behavioural Sciences, EHESP School of Public Health, Sorbonne Paris Cité, Rennes, France

2. UMR190 'Emergence des Pathologies Virales' (Aix-Marseille Univ. - IRD French Institute of Research for Development - EHESP French School of Public Health), Marseille, France

3. Institut National de la Santé et de la Recherche Médicale (INSERM; French National Institute of Health and Medical Research), UMR-S 707, Paris, France

4. University Pierre et Marie Curie-Paris 6, UMR-S 707, Paris, France

5. Assistance Publique-Hôpitaux de Paris (Public Assistance - Paris Hospitals), Hospital Saint Antoine, Public Health Unit, Paris, France

6. Centre national de la recherche scientifique (National Center for Scientific Research), Paris France

Citation style for this article:

Caille-Brillet AL, Raude J, Lapidus N, De Lamballerie X, Carrat F, Setbon M. Trends in influenza vaccination behaviours - results from the CoPanFlu cohort, France, 2006 to 2011. Euro Surveill. 2013;18(45):pii=20628. Available online: http://www.eurosurveillance.org/ViewArticle.aspx?Articleld=20628

Controversies over the effectiveness and safety of the pandemic influenza $A\left(\mathrm{H}_{1} \mathrm{~N}_{1}\right)$ pdmog vaccine in 2009/10 may have altered the influenza vaccination coverage in France after the pandemic season. The purpose of this study was to determine whether the pandemic affected seasonal influenza vaccination behaviours in the general population by analysing vaccination behaviours from $2006 / 07$ to $2011 / 12$ among the 1,451 subjects of the Cohort for Pandemic Influenza (CoPanFlu) France. We found that vaccination behaviours in 2010/11 and 2011/12 significantly differed from behaviours before the pandemic, with the notable exception of the targeted risk groups for seasonal influenza-related complications. Among the population with no risk factors, the post-pandemic influenza vaccine coverage decreased, with people aged 15 to 24 years and 45 to 64 years being most likely to abandon vaccination. Therefore, this study documents a moderate negative effect of the 2009/10 pandemic episode on vaccination behaviours in the French metropolitan population that was apparent also in the following two seasons. Moreover, it does not exclude that the general trend of reduced vaccination has also affected certain targeted groups at high risk for complications.

\section{Introduction}

The public health response to the 2009 pandemic of influenza $A\left(\mathrm{H}_{1} \mathrm{~N}_{1}\right)$ pdmo9, which first appeared in May 2009 in France, as in many European countries, largely focused on vaccination [1]. From June 2009, the question of vaccine availability was replaced in France by a growing controversy on the relevance and safety of pandemic vaccination and possible conflicts of interest between pharmaceutical companies and experts $[2,3]$. Two vaccines became available during the 2009/10 pandemic season in France: first a vaccine against seasonal influenza strains (seasonal vaccine), and later a vaccine against the pandemic strain (pandemic vaccine). French health authorities launched campaigns to promote both seasonal and pandemic vaccinations, aimed at protecting the entire population [4], but especially targeting usual and new risk groups [5]. In January 2010, the number of influenza infections was under the epidemic threshold in metropolitan France and the vaccination campaigns subsequently stopped.

Only around $8 \%$ of the French population got vaccinated against pandemic influenza $[2,3]$. A considerable body of research has been devoted to the failure of the 2009/10 pandemic vaccination campaign [6] and to the determinants of intentions and decisions to get this vaccine [7-9]. Yet few studies have examined the potential effect of controversies about vaccines on people's general vaccination behaviours and the rare studies addressing change in influenza vaccination behaviours in Europe after the pandemic have mostly focused on high-risk groups [10-12]. The purpose of this article is to further examine the evolution of influenza vaccination behaviours in relation to the pandemic: (i) whether and how influenza vaccination behaviours after the pandemic changed, and (ii) if some population groups, especially target groups, were particularly affected in their behaviours.

\section{Methods}

For this study, longitudinal data from the Cohort for Pandemic Influenza (CoPanFlu) France interdisciplinary consortium were used. The cohort consists of 1,451 individuals from 575 households representative of the French population, and was set up in December 2009 to study the risk of influenza $A\left(\mathrm{H}_{1} \mathrm{~N}_{1}\right)$ pdmog infection and its determinants. Study design, e.g. sampling methods, eligibility criteria and data collection have been described in detail elsewhere [13]. The research ethics committee 'Comité de Protection des Personnes Ile-de-France 1' approved the protocol of the study, and 
TABLE 1

Sociodemographic characteristics of the CoPanFlu cohort subjects, France, 2009-2012 (n=1,451)

\begin{tabular}{|c|c|c|c|}
\hline & $\mathrm{n}$ & $\begin{array}{c}\% \text { of } \\
\text { the } \\
\text { sample }\end{array}$ & $95 \% \mathrm{Cl}$ \\
\hline \multicolumn{4}{|l|}{ Sex } \\
\hline Male & 685 & 47.2 & $44.6-49.8$ \\
\hline Female & 766 & 52.8 & $50.2-55.4$ \\
\hline \multicolumn{4}{|l|}{ Age group at the inclusion } \\
\hline Under 15 years & 276 & 19.0 & $17.0-21.0$ \\
\hline $15-24$ years & 161 & 11.1 & $9 \cdot 5^{-12.7}$ \\
\hline $25-34$ years & 142 & 9.8 & $8.3-11.3$ \\
\hline $35-44$ years & 200 & 13.8 & $12.0-15.6$ \\
\hline $45-54$ years & 219 & 15.1 & $13 \cdot 3-16.9$ \\
\hline $55-64$ years & 237 & 16.3 & $14 \cdot 4-18.2$ \\
\hline 65 and older & 216 & 14.9 & $13.1-16.7$ \\
\hline \multicolumn{4}{|l|}{ Target groups } \\
\hline 65 years and older & 216 & 14.9 & $13.1-16.7$ \\
\hline $\begin{array}{l}\text { Under } 65 \text { years with a target } \\
\text { condition }\end{array}$ & 184 & 12.7 & $11.0-14 \cdot 4$ \\
\hline No risk factors & 1,051 & 72.4 & $70.1-74 \cdot 7$ \\
\hline \multicolumn{4}{|l|}{ Educational level } \\
\hline Primary education and lower & 104 & 7.2 & $5 \cdot 9-8.5$ \\
\hline Secondary education & 327 & 22.5 & $20.4-24.6$ \\
\hline Upper secondary education & 243 & 16.7 & $14.8-18.6$ \\
\hline Higher education & 419 & 28.9 & $26.6-31.2$ \\
\hline Information not available & 358 & $24 \cdot 7$ & $22.5-26.9$ \\
\hline \multicolumn{4}{|l|}{ Monthly household income } \\
\hline Under EUR 1,500 & 215 & 14.8 & $13.0-16.6$ \\
\hline EUR $1,500-3,000$ & 522 & 36.0 & $33 \cdot 5-38.5$ \\
\hline EUR 3,000-4,500 & 421 & 29.0 & $26.7-31.3$ \\
\hline EUR 4,500 and higher & 200 & 13.8 & $12.0-15.6$ \\
\hline Information not available & 93 & 6.4 & $5.1-7.7$ \\
\hline Total & 1,451 & 100.0 & \\
\hline
\end{tabular}

$\mathrm{Cl}$ : confidence interval.

informed consent was collected for each subject at the inclusion phase. In 2010/11, 37 subjects had left the study ( $2.5 \%$ of the sample), and a further 94 individuals (131 in total, $9.0 \%$ of the sample) had left the study when the research protocol has been extended to the 2011/12 season. Their sociodemographic characteristics were not significantly different from the rest of the cohort.

\section{Measures}

This study presents data on vaccination behaviours from the influenza seasons 2006/07 to 2011/12, collected among all 1,451 individuals of the cohort. During the inclusion visit that took place between December
2009 and July 2010, the participants declared whether they had received the influenza vaccination during the three seasons before the pandemic (2006/07, 2007/08 and 2008/09) and the seasonal, pandemic or both influenza vaccinations in $2009 / 10$. During follow-up visits and in questionnaires, cohort subjects were asked to report their vaccination status in 2010/11 and in 2011/12. At inclusion, subjects also provided their sociodemographic characteristics, which are presented in Table 1.

Data on education were divided into four levels using the 1997 International Standard Classification of Education developed by UNESCO and adapted for France by the Eurydice network [14]. Information on educational level was mostly unavailable for children under the age of 15 years.

Risk groups were defined using criteria for seasonal influenza vaccination before the $\mathrm{H}_{1} \mathrm{~N}_{1}$ influenza pandemic, as vaccination is recommended by the French health insurance system and free of charge for individuals with a risk factor for complications in case of an infection (65 years or older and some medical conditions) $[12,15]$. Two target (at-risk) groups were differentiated according to their age and clinical data collected during the inclusion visit: subjects aged 65 years and older at the inclusion visit (who may or may not have a condition placing them in a risk group) and those aged younger than 65 years with a risk condition.

\section{Statistical analysis}

Differences in independent groups were tested using a two-tailed Pearson's chi-square test. The McNemar test and the Cochran test, respectively, were applied to test the significance of changes in (dependent) vaccination behaviours of the cohort's subjects between two and more than two seasons [16]. A series of logistic regression analyses was performed to examine the association between vaccination behaviours and a range of sociodemographic factors. All statistical analysis was executed using IBM SPSS statistics version 20.

\section{Results}

Behavioural change during the pandemic in the cohort

Variations in vaccination behaviours before, during and after the pandemic were first investigated ( $p<0.0001$, Tables 2 and 3). Before the pandemic, vaccination behaviours were not significantly different over time, and influenza vaccination coverage (IVC) remained stable over the period from 2006/07 (20.6\%, 95\% confidence interval (Cl): 18.5-22.1), 2007/08 (20.6\%, 95\% $\mathrm{Cl}: 18.5-22.1)$ to $2008 / 09$ (21.3\%, $95 \% \mathrm{Cl}: 19.2-23.1$, Cochran test not significant).

As shown in the Figure, vaccination behaviours changed significantly during and after the pandemic season. In 2009/10, an increase in total IVC (for all influenza vaccines combined) can be observed compared to the 
Influenza vaccination coverage in the CoPanFlu cohort from 2006/07 to 2011/12, all data, France $(\mathrm{n}=1,451)$

\begin{tabular}{|c|c|c|c|c|c|c|c|c|c|c|c|c|c|}
\hline \multirow{3}{*}{$\begin{array}{l}\text { Influenza } \\
\text { season }\end{array}$} & \multicolumn{12}{|c|}{ Vaccination status (pandemic, seasonal or both vaccines) } & \multirow{3}{*}{$\begin{array}{c}\text { Total } \\
\mathrm{n}\end{array}$} \\
\hline & \multicolumn{3}{|c|}{ Vaccinated } & \multicolumn{3}{|c|}{ Not vaccinated } & \multicolumn{3}{|c|}{ Don't remember } & \multicolumn{3}{|c|}{ Missing data } & \\
\hline & $\mathrm{n}$ & $\%$ & $95 \% \mathrm{Cl}$ & $\mathrm{n}$ & $\%$ & $95 \% \mathrm{Cl}$ & $\mathrm{n}$ & $\%$ & $95 \% \mathrm{Cl}$ & $\mathrm{n}$ & $\%$ & $95 \% \mathrm{Cl}$ & \\
\hline $2006 / 07$ & 287 & 20.6 & $18.5-22.7$ & 1,090 & 78.1 & $75.9-80.3$ & 13 & 0.9 & $0.4-1.4$ & 6 & 0.4 & $0.1-0.8$ & 1,396 \\
\hline $2007 / 08$ & 292 & 20.6 & $18.5-22.7$ & 1,107 & 78.2 & $76.0-80.4$ & 9 & 0.6 & $0.2-1.0$ & 7 & 0.5 & $0.1-0.8$ & 1,415 \\
\hline $2008 / 09$ & 304 & 21.3 & $19.2-23.4$ & 1,114 & 77.9 & $75.8-80.0$ & 6 & 0.4 & $0.1-0.7$ & 6 & 0.4 & $0.1-0.7$ & 1,430 \\
\hline $2009 / 10^{a}$ & 240 & 16.5 & $14.6-18.5$ & \multirow{3}{*}{1,025} & \multirow{3}{*}{70.6} & \multirow{3}{*}{$68.3-73.0$} & \multirow{3}{*}{1} & \multirow{3}{*}{0.1} & \multirow{3}{*}{$0.0-0.2$} & \multirow{3}{*}{0} & \multirow{3}{*}{0.0} & \multirow{3}{*}{$0.0-0.0$} & \multirow{3}{*}{1,451} \\
\hline $2009 / 10^{b}$ & 100 & 6.9 & $5.6-8.2$ & & & & & & & & & & \\
\hline $2009 / 10^{c}$ & 85 & 5.9 & $4.7-7.1$ & & & & & & & & & & \\
\hline 2010/11 & 253 & 17.9 & $15.9-19.9$ & 1,158 & 81.9 & $79.9-83.9$ & 0 & 0.0 & $0.0-0.0$ & 3 & 0.2 & $0.0-0.5$ & 1,414 \\
\hline $2011 / 12$ & 253 & 19.2 & $17.1-21.3$ & 1,059 & 80.2 & $78.1-82.4$ & 7 & 0.5 & $0.1-0.9$ & 1 & 0.1 & $0.0-0.2$ & 1,320 \\
\hline
\end{tabular}

$\mathrm{Cl}$ : confidence interval.

a Seasonal vaccination only.

b Pandemic vaccination only.

c Both vaccinations.

\section{TABLE 3}

Influenza vaccination coverage in the CoPanFlu cohort from 2006/07 to 2011/12, excluding missing data, France (n=1,451)

\begin{tabular}{|c|c|c|c|c|c|c|c|}
\hline \multirow{3}{*}{ Influenza season } & \multicolumn{6}{|c|}{ Vaccination status ${ }^{a}$ (pandemic, seasonal or both vaccines) } & \multirow{3}{*}{$\begin{array}{c}\text { Total } \\
\mathrm{n}\end{array}$} \\
\hline & \multicolumn{3}{|c|}{ Vaccinated } & \multicolumn{3}{|c|}{ Not vaccinated } & \\
\hline & $\mathrm{n}$ & $\%$ & $95 \% \mathrm{Cl}$ & $\mathrm{n}$ & $\%$ & $95 \% \mathrm{Cl}$ & \\
\hline $2006 / 07$ & 287 & 20.8 & $18.7-22.9$ & 1,090 & 79.2 & $77.1-81.3$ & 1,377 \\
\hline $2007 / 08$ & 292 & 20.9 & $18.8-23.0$ & 1,107 & 79.1 & $77.0-81.2$ & 1,399 \\
\hline $2008 / 09$ & 304 & 21.4 & $19.3-23.5$ & 1,114 & 78.6 & $76.5-80.7$ & 1,418 \\
\hline $2009 / 10^{b}$ & 240 & 16.6 & $14.7-18.5$ & \multirow{3}{*}{1,025} & \multirow{3}{*}{70.7} & \multirow{3}{*}{$68.4-73.0$} & \multirow{3}{*}{1,450} \\
\hline $2009 / 10^{c}$ & 100 & 6.9 & $5.6-8.2$ & & & & \\
\hline $2009 / 10^{d}$ & 85 & 5.9 & $4.7-7.1$ & & & & \\
\hline $2010 / 11$ & 253 & 17.9 & $15.9-19.9$ & 1,158 & 82.1 & $80.1-84.1$ & 1,411 \\
\hline $2011 / 12$ & 253 & $19 \cdot 3$ & $17.2-21.4$ & 1,059 & 80.7 & $78.6-82.8$ & 1,312 \\
\hline
\end{tabular}

$\mathrm{Cl}$ : confidence interval.

a The missing data are excluded.

b Seasonal vaccination only.

c Pandemic vaccination only.

d Both vaccinations.

2008/09 season (29.4\%, 95\% Cl: 27.1-31.7, p<0.0001), with an IVC for the pandemic vaccine (only or in combination with the seasonal vaccine) of $12.8 \%$ (95\% Cl: 11.1-14.5) and an IVC for the seasonal vaccine (only or in combination with the pandemic vaccine) of $22.5 \%$ (95\% Cl: 20.4-24.6). It should be mentioned that $5.9 \%$ of the sample received both vaccines (95\% Cl: 4.7-7.1, Table 3). However, the total seasonal IVC in 2009/10 was not significantly higher than in $2008 / 09$.

Among subjects who had not left the study in 2011/12, the total IVC was significantly lower in 2010/11 than the total seasonal IVC in 2009/10, with a decrease of $17.9 \%$ (95\% Cl: 15.9-19.9, p<0.0001). Among subjects who had not left the study in 2011/12, vaccination behaviours in 2011/12 were not significantly different from those observed in 2010/11. Using paired tests and considering subjects who were still in the study in 2010/11 and in 2011/12, respectively, vaccination behaviours in 2010/11 and in 2011/12 were significantly different from those observed in 2008/09, with lower IVCs after the pandemic ( $p<0.0001)$. 
Influenza vaccination coverage from $2006 / 07$ to 2011/12 in the total CoPanFlu cohort and according to risk factors for seasonal influenza, France ( $n=1,451$ until 2009/10, n=1,414 in 2010/11, n=1,320 in 2011/12)
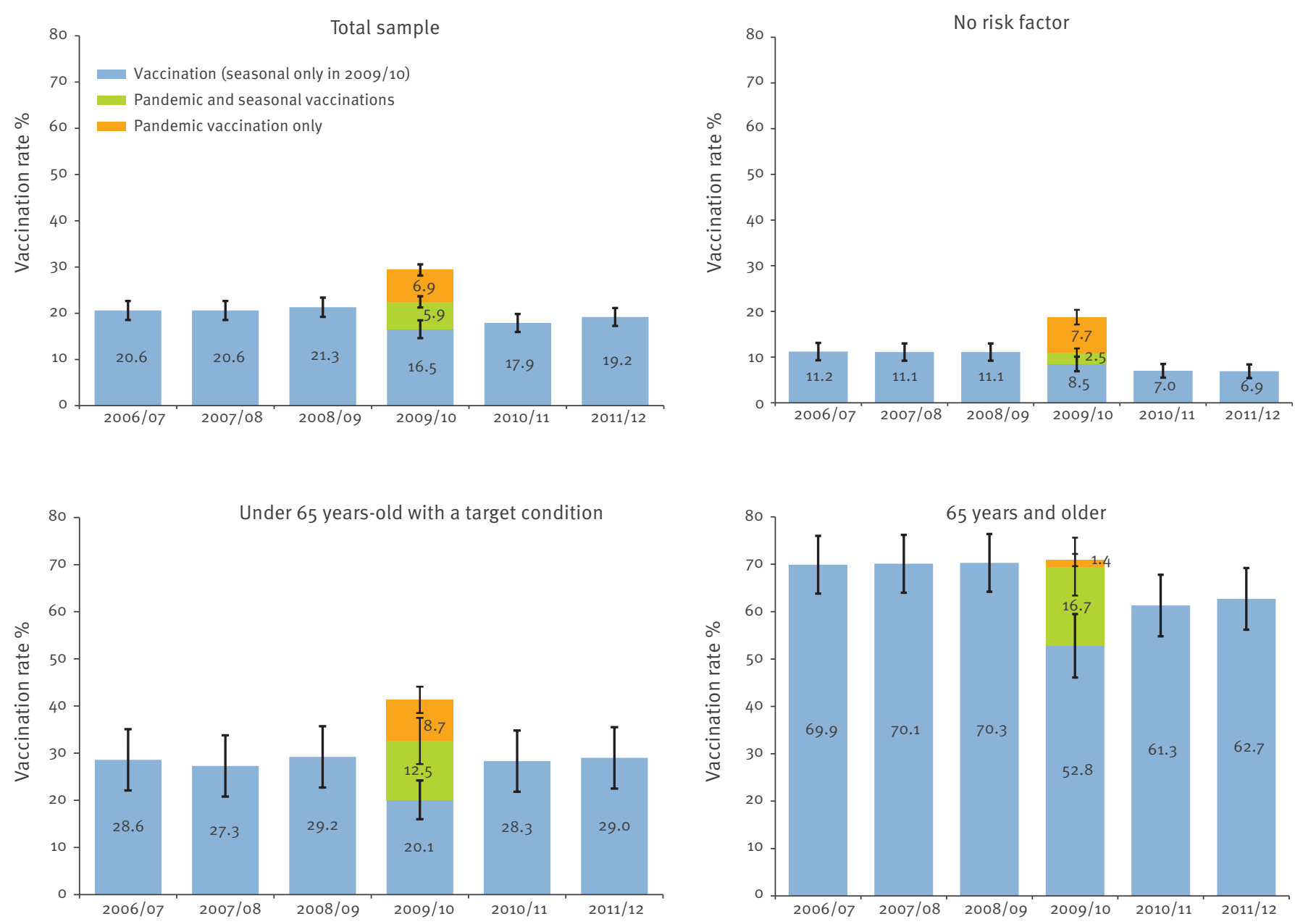

Behavioural change during the pandemic according to risk factors

Vaccination behaviours varied according to the presence of risk factors (Pearson's chi-square test, p 0.0001 , Figure), with people with no risk factor not surprisingly demonstrating the lowest IVCs across all seasons. Similarly to the general population, their vaccination behaviours were stable before the pandemic, an IVC increase was noted in 2009/10 and a decrease in $2010 / 11$.

Among target groups, individuals aged 65 years and over had better coverage before, during and after the pandemic than those younger than 65 years with a target condition or those with no risk factor (Pearson's chi-square test, pro.0001). In 2008/09, the season before the pandemic, IVCs ranged from $70.3 \%(95 \%$ $\mathrm{Cl}$ : 64.2-76.4) for individuals aged 65 years and over to only $29.2 \%$ ( $95 \% \mathrm{Cl}: \mathbf{2 2 . 7 - 3 5 . 7 )}$ for those under age 65 years with a target condition, and $11.1 \%(95 \% \mathrm{Cl}$ : 9.2-13.0) for individuals with no risk factor (Figure). Compared with $2008 / 09$, only the subjects younger than 65 years with a target condition increased their total seasonal IVC in 2009/10 (seasonal vaccine only or seasonal and pandemic) to $32.6 \%$ (95\% Cl: 30.2-35.0, pro.05) (Figure).

During the pandemic, subjects with no risk factor (as defined for seasonal influenza) were significantly less likely to be vaccinated than the two target groups (p<o.0001), almost as likely to use the pandemic vaccine $(7.7 \%, 95 \% \mathrm{Cl}: 6.4-9.1)$ as the seasonal vaccine (8.5\%, 95\% Cl: 7.1-9.9) and rarely got immunised against both strains $(2.5 \%, 95 \% \mathrm{Cl}: 1.7-3.3)$. Among target groups, subjects 65 years and older almost never got vaccinated against the pandemic strain only $(1.4 \%, 95 \% \mathrm{Cl}: 0.8-2.0)$ and rather used it in addition to the seasonal vaccine $(16.7 \%$, $95 \% \mathrm{Cl}: 14.8-18.6)$. More than half of this latter target group got vaccinated only against the seasonal strain of influenza $(52.8 \%, 95 \%$ $\mathrm{Cl}$ : 50.2-55.4). Those under age 65 years at high risk for complications had the greatest total uptake of the pandemic vaccine compared with the two other groups (21.2\%, 95\% Cl: 19.1-23.3, pro.001) with 8.7\% (95\% 
$\mathrm{Cl}$ : 7.2-10.1) who got immunised only against the pandemic strain. Similar to those aged 65 years and over, persons under 65 years with a target condition relied more strongly on both vaccines that year $(12.5 \%, 95 \%$ $\mathrm{Cl}: 10.8-14.2)$ and on the seasonal vaccine only $(20.1 \%$, 95\% Cl: 18.0-22.2).

\section{Behavioural change after the pandemic}

Vaccination behaviours in 2010/11 of subjects who were vaccinated in 2008/09 and had not left the study in 2010/11 $(n=293)$ were then studied. Significant changes in vaccination behaviour were observed in the cohort after the pandemic season: $27.0 \%$ of the total sample vaccinated in 2008/09 did not get vaccinated again in 2010/11 (Table 4). The change in vaccination behaviours was significantly different according to risk factors (Pearson's chi-square test, p<0.0001): $45.4 \%$ of individuals with no risk factor, $21.6 \%$ of those under age 65 years with a target condition, and $14.2 \%$ of individuals aged 65 years and over abandoned influenza vaccination. In fact, considering individuals who had not left the study, vaccination behaviours in 2010/11 and in 2011/12 among people at high risk for complications were not statistically different from those adopted in the three seasons before the pandemic, whereas a significant IVC decrease was observed after the pandemic among subjects with no risk factor.

\section{Sociodemographic characteristics}

associated with vaccination behaviours

As a final measure, we explored sociodemographic factors associated with getting vaccinated in 2008/09 and with not getting vaccinated again in 2010/11 (for subjects with no risk factor and vaccinated in 2008/09). As the number of participants who were unvaccinated in the 2008/09 season and got vaccinated in the postpandemic season was rather low, we decided not to perform a statistical analysis for this group.

In univariate analysis, getting vaccinated in 2008/09 was positively associated with every age group (compared with individuals under 15 years of age), with level of household income, as well as with primary education (unadjusted odds ratio (OR): 3.16 , 95\% Cl: $1.52-$ 6.57), but negatively associated with no information on education (unadjusted OR: $0.34,95 \% \mathrm{Cl}: 0.18-0.69$, compared with individuals with a higher education). As indicated in Tables 5 and 6, age and household income level remained significantly associated with the dependant variable in multivariate analysis.

Change in vaccination behaviours among subjects with no risk factor was positively associated with every age group (except an age equal to or older than 65 years, as they were excluded from the analysis) but strongest among individuals aged 15 to 24 years (adjusted OR: 10.75, $95 \% \mathrm{Cl}: 3.03-38.18$ ), those aged 45 to 54 years (adjusted OR: $10.58,95 \% \mathrm{Cl}: 2.91-38.53)$ and those aged 55 to 64 years (adjusted OR: 23.15 , 95\% Cl: 6.3983.85), compared with individuals under 15 years.

\section{Discussion}

As in many industrialised countries during the 2009 influenza $\mathrm{A}\left(\mathrm{H}_{1} \mathrm{~N}_{1}\right)$ pdmog pandemic, public health authorities in France faced a climate of distrust toward the pandemic vaccine [6], which was extensively covered by the mass media $[2,3]$. It should also be noted that the pandemic vaccination effort was contested by a number of medical professionals and politicians $[3,17]$. One of the objectives of this article was to ascertain the impact of the controversies on subsequent influenza vaccination behaviours.

An immediate impact on vaccination behaviour This study shows an immediate impact of the pandemic episode on vaccination uptake rates that lasted for the period of the two following seasons observed in this study. The longitudinal setting of the CoPanFlu cohort enabled us to characterise behaviour changes among the same representative sample of the French population before, during and after the pandemic, which is often lacking in the literature $[18,19]$. A clear immediate effect of the pandemic season on influenza vaccination behaviours could be established (Tables 2 and 3). Despite the low pandemic IVC also recorded in other studies $[2,3]$, cohort subjects were significantly more often vaccinated with the seasonal vaccine in 2009/10 compared with previous seasons, and sometimes got both vaccinations. Altogether, this resulted in a total IVC close to $30 \%$. Vaccination behaviours in the total sample were found to be affected for two years after the pandemic in that IVCs in 2010/11 and 2011/12 were significantly lower than before the pandemic (Table 4). However, this trend can only be confirmed for the people with no risk factor for seasonal influenza, as statistical power was lacking to reveal such an effect among members of the target groups. Regarding the general impact of the pandemic season on vaccination behaviours, this study is to our knowledge the first to reveal such a significant drop in IVC after the pandemic in a longitudinal setting. Whether this trend will continue has yet to be confirmed, as it raises concerns for future vaccination campaigns and among specific population groups.

Pandemic vaccination was in fact recommended for new target groups that were not included in the French definition of target groups before the pandemic: pregnant women, parents of young children, and subjects with other specific pathologies or aged over 19 years with no risk factor [5]. Some of these groups were still included in the 2010/11 influenza vaccination recommendations [20]. As with the rest of the population, older age groups were more willing to get vaccinated during the pandemic, but less so in the following seasons This is particularly illustrative of the controversial climate during the pandemic: individuals who got vaccinated against seasonal influenza before the pandemic season changed their behaviour. Controversies in 2009/10 and conflicts of interest between pharmaceutical companies and experts could have created doubts about the safety of influenza vaccines among 
TABLE 4

Influenza vaccination status in 2010/11 of CoPanFlu cohort subjects who were vaccinated in 2008/09, France ( $\mathrm{n}=293$ )

\begin{tabular}{|l|c|c|c|c|c|c|c|c|}
\hline \multirow{2}{*}{ Vaccinated in 2008/09 } & \multicolumn{5}{|c|}{ Vaccination status in 2010/11 (pandemic, seasonal or both vaccines) } \\
\cline { 2 - 9 } & $\begin{array}{c}\text { Remained } \\
\text { vaccinated }\end{array}$ & $\begin{array}{c}\text { Abandoned } \\
\text { vaccination }\end{array}$ & \multicolumn{2}{|c|}{ Missing data } & \multicolumn{2}{c|}{ Total } \\
\cline { 2 - 9 } & $\mathrm{n}$ & $\%$ & $\mathrm{n}$ & $\%$ & $\mathrm{n}$ & $\%$ & $\mathrm{n}$ & $\%$ \\
\hline Among the general population & 213 & 72.7 & 79 & 27.0 & 1 & 0.3 & 293 & 100.0 \\
\hline Among those with no risk factor & 59 & 54.6 & 49 & 45.4 & 0 & 0.0 & 108 & 100.0 \\
\hline Among those under 65 years (in 2010/11) with a target condition & 40 & 78.4 & 11 & 21.6 & 0 & 0.0 & 51 & 100.0 \\
\hline Among those over 65 years and older (in 2010/11) & 114 & 85.1 & 19 & 14.2 & 1 & 0.7 & 134 & 100.0 \\
\hline
\end{tabular}

\section{TABLE 5}

Factors associated with getting vaccinated in 2008/09 and with getting vaccinated in 2008/09 (n=111) and abandoning vaccination in 2010/11 $(\mathrm{n}=49)$, univariate analysis, France

\begin{tabular}{|c|c|c|c|c|c|c|c|c|}
\hline \multirow[t]{2}{*}{ Factors } & \multicolumn{4}{|c|}{$\begin{array}{l}\text { Dependant variable: vaccinated } \\
\text { (with any influenza vaccine) } \\
\text { in } 2008 / 09(\mathrm{n}=111)(1)\end{array}$} & \multicolumn{4}{|c|}{$\begin{array}{l}\text { Dependant variable: vaccinated } \\
\text { (with any influenza vaccine) in } 2008 / 09 \text { and } \\
\text { abandoned vaccination in } 2010 / 11(n=49)(2)\end{array}$} \\
\hline & $\mathrm{n}$ & Unadjusted OR & $95 \% \mathrm{Cl}$ & $p$ value & $\mathrm{n}$ & Unadjusted OR & $95 \% \mathrm{Cl}$ & $\mathrm{p}$ value \\
\hline \multicolumn{9}{|l|}{ Sex } \\
\hline Male & 488 & 0.95 & $0.64-1.41$ & 0.784 & 552 & 1.13 & $0.64-2.01$ & 0.676 \\
\hline Female & 562 & Reference & & & 470 & Reference & & \\
\hline \multicolumn{5}{|l|}{ Age group in $2008 / 09$} & \multicolumn{4}{|c|}{ Age group in $2010 / 11$} \\
\hline Under 15 years & 279 & Reference & & & 250 & Reference & & \\
\hline $15-24$ years & 124 & 6.17 & $2.49-15.31$ & $<0.0001$ & 141 & 7.46 & $1.56-35.63$ & 0.012 \\
\hline $25-34$ years & 141 & 3.29 & $1.25-8.68$ & 0.016 & 125 & 10.78 & $2.33-50.01$ & 0.002 \\
\hline $35-44$ years & 175 & 2.86 & $1.10-7.41$ & 0.030 & 169 & 4.56 & $0.91-22.89$ & 0.065 \\
\hline $45-54$ years & 166 & 6.89 & $2.91-16.32$ & $<0.0001$ & 171 & 6.89 & $1.47-32.29$ & 0.014 \\
\hline $55-64$ years & 165 & 14.57 & $6.39-33.24$ & $<0.0001$ & 166 & 11.42 & $2.56-50.95$ & 0.001 \\
\hline \multicolumn{9}{|l|}{ Educational level } \\
\hline Information not available & 309 & 0.34 & $0.17-0.67$ & 0.002 & 310 & 0.48 & $0.19-1.20$ & 0.117 \\
\hline $\begin{array}{l}\text { Primary education and } \\
\text { lower }\end{array}$ & 49 & 3.16 & $1.52-6.57$ & 0.002 & 42 & 2.18 & $0.68-6.97$ & 0.188 \\
\hline Secondary education & 221 & 1.28 & $0.76-2.14$ & 0.355 & 213 & 1.46 & $0.68-3.12$ & 0.333 \\
\hline $\begin{array}{l}\text { Upper secondary } \\
\text { education }\end{array}$ & 159 & 1.50 & $0.87-2.59$ & 0.145 & 153 & 1.45 & $0.63-3.34$ & 0.385 \\
\hline Higher education & 312 & Reference & & & 304 & Reference & & \\
\hline \multicolumn{9}{|l|}{ Monthly household income } \\
\hline Information not available & 50 & 0.41 & $0.14-1.23$ & 0.112 & 53 & 0.71 & $0.15-3.46$ & 0.672 \\
\hline Under EUR 1,500 & 140 & 0.45 & $0.22-0.93$ & 0.031 & 134 & 0.85 & $0.29-2.51$ & 0.768 \\
\hline EUR $1,500-3,000$ & 385 & 0.47 & $0.27-0.81$ & 0.007 & 379 & 0.80 & $0.33-1.91$ & 0.613 \\
\hline EUR 3,000-4,500 & 318 & 0.69 & $0.40-1.17$ & 0.167 & 303 & 1.08 & $0.45-2.56$ & 0.866 \\
\hline EUR 4,500 and higher & 157 & Reference & & & 153 & Reference & & \\
\hline Total of the sample & 1,050 & & & & 1,022 & & & \\
\hline
\end{tabular}


Factors associated with getting vaccinated in 2008/09 and with getting vaccinated in 2008/09 (n=111) and abandoning vaccination in 2010/11 $(\mathrm{n}=49)$, multivariate analysis, France

\begin{tabular}{|c|c|c|c|c|c|c|c|c|}
\hline \multirow[t]{2}{*}{ Factors } & \multicolumn{4}{|c|}{$\begin{array}{l}\text { Dependant variable: vaccinated } \\
\text { (with any influenza vaccine) } \\
\text { in } 2008 / 09(\mathrm{n}=111)(1)\end{array}$} & \multicolumn{4}{|c|}{$\begin{array}{l}\text { Dependant variable: vaccinated } \\
\text { (with any influenza vaccine) in } 2008 / 09 \text { and } \\
\text { abandoned vaccination in } 2010 / 11(n=49)(2)\end{array}$} \\
\hline & $\mathrm{n}$ & Adjusted OR & $95 \% \mathrm{Cl}$ & $p$ value & $n$ & Adjusted OR & $95 \% \mathrm{Cl}$ & $\mathrm{p}$ value \\
\hline \multicolumn{9}{|l|}{ Sex } \\
\hline Male & 488 & 0.98 & $0.65-1.48$ & 0.923 & 552 & 1.10 & $0.61-1.98$ & 0.757 \\
\hline Female & 562 & Reference & & & 470 & Reference & & \\
\hline \multicolumn{5}{|l|}{ Age group in $2008 / 09$} & \multicolumn{4}{|c|}{ Age group in $2010 / 11$} \\
\hline Under 15 years & 279 & Reference & & & 250 & Reference & & \\
\hline $15-24$ years & 124 & 10.75 & $3.03-38.18$ & $<0.0001$ & 141 & 10.65 & $1.95-58.18$ & 0.006 \\
\hline $25-34$ years & 141 & 6.65 & $1.67-26.60$ & 0.007 & 125 & 23.70 & $3.58-157.16$ & 0.001 \\
\hline $35-44$ years & 175 & 4.80 & $1.23-18.68$ & 0.024 & 169 & 8.31 & $1.19-57.92$ & 0.033 \\
\hline $45-54$ years & 166 & 10.58 & $2.91-38.53$ & $<0.0001$ & 171 & 10.83 & $1.65-71.31$ & 0.013 \\
\hline $55-64$ years & 165 & 23.15 & $6.39-83.85$ & $<0.0001$ & 166 & 18.35 & $2.88-116.97$ & 0.002 \\
\hline \multicolumn{9}{|l|}{ Educational level } \\
\hline Information not available & 309 & 2.21 & $0.76-6.44$ & 0.144 & 310 & 2.58 & $0.76-8.77$ & 0.129 \\
\hline $\begin{array}{l}\text { Primary education and } \\
\text { lower }\end{array}$ & 49 & 3.32 & $1.45-7.57$ & 0.004 & 42 & 2.67 & $0.75-9.50$ & 0.130 \\
\hline Secondary education & 221 & 1.52 & $0.86-2.67$ & 0.150 & 213 & 1.85 & $0.81-4.21$ & 0.146 \\
\hline $\begin{array}{l}\text { Upper secondary } \\
\text { education }\end{array}$ & 159 & 1.61 & $0.90-2.87$ & 0.106 & 153 & 1.67 & $0.70-3.96$ & 0.246 \\
\hline Higher education & 312 & Reference & & & 304 & Reference & & 0.386 \\
\hline \multicolumn{9}{|l|}{ Monthly household income } \\
\hline Information not available & 50 & 0.21 & $0.07-0.67$ & 0.009 & 53 & 0.50 & $0.10-2.50$ & 0.395 \\
\hline Under EUR 1,500 & 140 & 0.30 & $0.14-0.68$ & 0.004 & 134 & 0.66 & $0.21-2.06$ & 0.470 \\
\hline EUR $1,500-3,000$ & 385 & 0.40 & $0.22-0.73$ & 0.003 & 379 & 0.63 & $0.25-1.58$ & 0.325 \\
\hline EUR 3,000-4,500 & 318 & 0.54 & $0.31-0.96$ & 0.037 & 303 & 0.91 & $0.38-2.21$ & 0.838 \\
\hline EUR 4,500 and higher & 157 & Reference & & & 153 & Reference & & 0.756 \\
\hline Total of the sample & 1,050 & & & & 1,022 & & & \\
\hline
\end{tabular}

$\mathrm{Cl}$ : confidence interval; OR: odds ratio.

the French population, as these factors have been documented to discourage vaccination behaviours [6-8,21]. This led not only to a low pandemic IVC in $2009 / 10$ but also to subjects not renewing their vaccination behaviours in 2010/11. Especially concerning is this shift in vaccination behaviour among the age group 55 to 64 years, who will soon belong to the target group of people aged 65 years and over.

These results attest to a specific impact of the pandemic on target groups (Tables 2 and 3). In CoPanFlu data, target groups more frequently adopted both seasonal [22] and pandemic [23,24] vaccines during the pandemic than people with no risk factor ( $p<0.0001)$. Target groups were in fact more likely to get both vaccinations than those with no risk factor, but subjects aged 65 years and over almost never relied only on the pandemic vaccine. Since past vaccination behaviours are known to influence later vaccination behaviours
$[1,6,18,24]$, and people aged 65 years and over demonstrated high and superior IVCs across time [17], they seemed to have continued their usual seasonal vaccination practices, and adopting the additional protection from the pandemic vaccine. On the other hand, individuals younger than 65 years were more likely to use only the pandemic vaccine and had had a lower adherence to seasonal vaccination before the pandemic than other risk groups.

In the CoPanFlu cohort, the 2009 influenza pandemic did not alter post-pandemic vaccination behaviours among target groups as found in another French study conducted in 2010/11 [17]. In fact, individuals with risk factors constitute priority target groups for influenza immunisation programmes in France as in most industrialised countries $[25,26]$ because they benefit most from the protection of the influenza vaccine [27], which would encourage them not to discontinue their 
vaccination behaviours. It is however, of public health concern that the vaccination coverage in those target groups is still insufficient, below the $75 \%$ recommended by the World Health Organization [28], as has already been highlighted in several studies before the pandemic $[15,16,25]$.

\section{Limitations and potential biases}

In the CoPanFlu cohort, vaccination behaviours were stable before the 2009 pandemic (Tables 2 and 3), similar to other French studies $[15,29]$. IVCs among people over 65 years were comparable to other data $[29,30]$, yet slightly lower than in the general population compared with previously published (though cross-sectional) results [31]. Prepandemic IVCs among individuals under 65 years with a risk condition were significantly lower (i.e. ranging from $34 \%$ to $38.3 \%$ ) than those observed in other studies [29,30]. Moreover, the criteria for target groups used in this study were based on less restrictive clinical criteria (suffering or having suffered from a specific condition) those that of the French health insurance (i.e. based on enrolment in the long-term chronic disease programme for these specific diseases). Finally, the 2009/10 pandemic IVC in this cohort was higher than the $8 \%$ coverage observed in France [2,3], although in line with the IVC estimate of $11.1 \%$ from another French study on IVC during the pandemic [24].

We initially used participants' age at the inclusion as a default and stable variable in the results. When comparing behaviours between two seasons, we considered age at the later season to test for a behavioural change among subjects younger than 65 years who could have entered the risk group of people aged over 65 of age. However, even if some IVCs and results of the paired tests differed, the differences observed over time remained insignificant.

The CoPanFlu France cohort was originally designed to assess the relative risk of infection by the influenza $A\left(\mathrm{H}_{1} \mathrm{~N}_{1}\right)$ pdmog virus, not the uptake of influenza vaccination. As indicated in a methodological paper by Lapidus et al. in 2012 [13]: We first intended to include 1000 households (about 2100 subjects) which would have permitted to detect covariates associated to a relative risk $\geq 1.4$ with a $80 \%$ power and $5 \%$ significance, assuming a cumulative incidence of $10 \%$ and intrahousehold correlation of 0.3. However, due to organisational and financial constraints, only 575 households (1,451 subjects) were eventually included in the cohort. Theoretically, the maximal margin of error with a $95 \%$ $\mathrm{Cl}$ is \pm 2.6 for a random sample of 1,451 individuals and \pm 2.2 for a random sample of 2,000 individuals. Due to the sample size and the possible subsequent lack of statistical power, changes in vaccination behaviours may have been more substantial in some population groups.

\section{Conclusion}

These data illustrate the power of prospective household study designs to investigate behavioural changes in a context of global health crises. Contrary to Guthmann and colleagues [17], our study attests to a more lasting impact of the pandemic over the following two seasons, ultimately causing a decrease in IVC (with the possible exception of certain target groups at risk for complications). Secondly, it highlighted that people with no risk factors, and among them, young adults aged 24 to 34 years and people aged 45 to 64 years, were more affected by this trend. Although these groups could have been targeted by the pandemic vaccination campaign, this may also be influenced by the fact that influenza vaccination is not generally free of charge for these non-risk groups. Further studies should assess if this decreasing post-pandemic IVC trend is a temporary side-effect of the pandemic season or an indicator of a longer-lasting disaffection with the seasonal influenza vaccine or with vaccination in general, especially among at-risk populations. To do so, determinants of vaccination behaviours and motivations to get or not to get vaccinated should be more closely monitored.

\section{Acknowledgements}

This study was supported by the Institut de Microbiologie et Maladies Infectieuses (IMMI-AVIESAN), the Institut de Santé Publique (ISP-AVIESAN), the French Ministry of Health and Assistance Publique Hôpitaux de Paris-PHRC 2010 \#AOM10199, the French Ministry of research and the Institut de Recherche en Sante Publique (IReSP-TGIR 2009). The EHESP supported a part of the financing of the "Risk perceptions and preventive behaviours" questionnaire.

\section{Conflict of interest}

None declared.

Authors' contributions

Caille-Brillet Anne-Laure, Raude Jocelyn, Setbon Michel designed the purpose of this article and all authors contributed to the analysis and the interpretation of the data.

Caille-Brillet Anne-Laure and Lapidus Nathanaël conducted all statistical analyses.

All authors participated in the drafting and revision of this manuscript and gave their final approval of this version.

All members of the Scientific Committee of the CoPanFlu France consortium approved the final version of the manuscript: Antoine Flahault, Laurent Andreoletti, Pierre-Yves Boelle, Simon Cauchemez, Marie-Lise Gougeon, Michele Legeas, Marianne Leruez-Ville, Michael Schwarzinger and Eric Vivier. A special thanks to Lore Leighton (EHESP) for her careful corrections of this manuscript. 


\section{References}

1. World Health Organization (WHO). Pandemic influenza preparedness framework for the sharing of influenza viruses and access to vaccines and other benefits. Geneva: WHO; 2011. Available from: http://whqlibdoc.who.int/ publications/2011/9789241503082_eng.pdf

2. Lagarde J, Door J. Rapport fait de la commission d'enquête sur la manière dont a été programmé, expliquée et gérée la campagne de vaccination contre la grippe $A\left(\mathrm{H}_{1} \mathrm{~N}_{1}\right)$. [Report of the commission investigating how the vaccination campaign against influenza $A\left(\mathrm{H}_{1} \mathrm{~N}_{1}\right)$ was planned, explained and managed]. Paris : Assemblée nationale; 2010. French. Available from: http://www.assemblee-nationale.fr/13/pdf/rap-enq/ r2698.pdf

3. Bone A, Guthmann JP, Nicolau J, Lévy-Bruhl D. Population and risk group uptake of $\mathrm{H}_{1} \mathrm{~N}_{1}$ influenza vaccine in mainland France 2009-2010: results of a national vaccination campaign. Vaccine. 2010;28(51):8157-61.

http://dx.doi.org/10.1016/j.vaccine.2010.09.096 PMid:20937310

4. Circulaire du 21 août 2009 Planification logistique d'une campagne de vaccination contre le nouveau virus $A\left(\mathrm{H}_{1} \mathrm{~N}_{1}\right)$. [Circular of 21 August 2009 Logistic plan of a vaccination campaign against the novel influenza $A\left(\mathrm{H}_{1} \mathrm{~N}_{1}\right]$. Paris: Ministère de l'Intérieur; 2009. French. Available from: http://www.sante. gouv.fr/IMG/pdf/circulaire_du_21_aout_2009.pdf

5. Haut Conseil de la santé publique. Actualisation de l'avis relatif aux recommandations sur les priorités sanitaires d'utilisation des vaccins pandémiques dirigés contre le virus grippal $A\left(\mathrm{H}_{1} \mathrm{~N}_{1}\right) v$. [Updated advice on recommendations on health priorities for the use of pandemic vaccines against the influenza $A\left(\mathrm{H}_{1} \mathrm{~N}_{1}\right)$ virus]. Paris : Haut Conseil de la santé publique; 2009. French. Available from: http://www.hcsp.fr/ docspdf/avisrapports/hcspa20091002_H1N1.pdf

6. Schwarzinger M, Flicoteaux R, Cortarenoda S, Obadia Y, Moatti J-P. Low Acceptability of $A / \mathrm{H}_{1} \mathrm{~N}_{1}$ Pandemic Vaccination in French Adult Population: Did Public Health Policy Fuel Public Dissonance? PLoS ONE. 2010;5(4):e10199. http://dx.doi.org/10.1371/journal.pone.0010199 PMid:20421908 PMCid:PMC 2856629

7. Liao QY, Cowling BJ, Lam WWT, Fielding R. Factors Affecting Intention to Receive and Self-Reported Receipt of 2009 Pandemic $\left(\mathrm{H}_{1} \mathrm{~N}_{1}\right)$ Vaccine in Hong Kong: A Longitudinal Study. PLoS ONE. 2011;6(3):e17713.

http://dx.doi.org/10.1371/journal.pone.0017713

PMid:21412418. PMCid:PMC3055876

8. Gaygısız Ü, Gaygısız E, Özkan T, Lajunen T. Why were Turks unwilling to accept the $\mathrm{A} / \mathrm{H}_{1} \mathrm{~N}_{1}$ influenza-pandemic vaccination? People's beliefs and perceptions about the swine flu outbreak and vaccine in the later stage of the epidemic. Vaccine. 2010;29(2):329-33.

http://dx.doi.org/10.1016/j.vaccine.2010.10.030

PMid:20979988

9. Gidengil CA, Parker AM, Zikmund-Fisher BJ. Trends in Risk Perceptions and Vaccination Intentions: A Longitudinal Study of the First Year of the $\mathrm{H}_{1} \mathrm{~N}_{1}$ Pandemic. Am J Public Health. 2012;102(4):672-9. http://dx.doi.org/10.2105/AJPH.2011.300407 PMid:22397349. PMCid:PMC3297965

10. Aguilar I, Reyes M, Martínez-Baz I, Guevara M, Albéniz E, Belza MJ, et al. Use of the vaccination register to evaluate influenza vaccine coverage in seniors in the 2010/11 influenza season, Navarre, Spain. Euro Surveill. 2012;17(17): pii=20154. Available from: http://www.eurosurveillance.org/ViewArticle. aspx?Articleld $=20154$ PMid:22551499

11. Martínez-Baz I, Aguilar I, Morán J, Albéniz E, Aldaz P, Castilla J. Factors associated with continued adherence to influenza vaccination in the elderly. Prev Med. 2012;55(3):246-50. http://dx.doi.org/10.1016/j.ypmed.2012.06.02 PMid:22759626

12. Tuppin P, Choukroun S, Samson S, Weill A, Ricordeau P, Allemand $\mathrm{H}$. Vaccination contre la grippe saisonnière en France en 2010 et 2011: diminution des taux de couverture et facteurs associés [Vaccination against seasonal influenza in France in 2010 and 2011: decrease of coverage rates and associated factors.]. Presse Med. 2012;41(11):e568-76. French. http://dx.doi.org/10.1016/j.lpm.2012.05.017 PMid:22795870

13. Lapidus N, de Lamballerie X, Salez N, Setbon M, Ferrari $P$, Delabre R, et al. Integrative study of pandemic $A / \mathrm{H}_{1} \mathrm{~N}_{1}$ influenza infections: design and methods of the CoPanFluFrance cohort. BMC Public Health. 2012;12:417. http://dx.doi.org/10.1186/1471-2458-12-417 PMid:22676272. PMCid:PMC3461458

14. Eurydice network. France. Overview. In: Eurypedia - The European Encyclopedia on National Education Systems.
Brussels: The Education, Audiovisual and Culture Executive Agency (EACEA). [Accessed: 4 Sep 2012]. Available from: https://webgate.ec.europa.eu/fpfis/mwikis/eurydice/index. php/France:Overview

15. Tuppin P, Samson S, Weill A, Ricordeau P, Allemand H. Taux de couverture vaccinale contre la grippe en France en 2007-2008: apport des données de remboursement du régime général. [Influenza vaccination coverage in France in 2007-2008: Contribution of vaccination refund data from the general health insurance scheme]. Med Mal Infect. 2009;39(10):780-8. French. http://dx.doi.org/10.1016/j.medmal.2009.08.013 PMid:19796899

16. Siegel S, Castellan NJ, Jr. Nonparametric statistics for the behavioral sciences. 2nd edition. New York: McGraw-Hill; 1988.

17. Guthmann J-P, Fonteneau L, Bonmarin I, Lévy-Bruhl D. Influenza vaccination coverage one year after the $A\left(\mathrm{H}_{1} \mathrm{~N}_{1}\right)$ influenza pandemic, France, 2010-2011. Vaccine. 2012;30(6):995-7. http://dx.doi.org/10.1016/j.vaccine.2011.12.011 PMid:22178520

18. Endrich MM, Blank PR, Szucs TD. Influenza vaccination uptake and socioeconomic determinants in 11 European countries. Vaccine. 2009;27(30):4018-24 http://dx.doi.org/10.1016/j.vaccine.2009.04.029 PMid:19389442

19. Macroepidemiology of influenza vaccination study group. The macroepidemiology of influenza vaccination in 56 countries, 1997-2003. Vaccine. 2005;23(44):5133-43. http://dx.doi.org/10.1016/j.vaccine.2005.06.010 PMid:16039762

20. Haut Conseil de la santé publique. Le Calendrier des vaccinations et les recommandations vaccinales 2012 selon l'avis du Haut conseil de la santé publique. [2012 vaccination schedule and recommendations from the Haut Conseil de la santé publique in France]. Bulletin épidémiologique hebdomadaire. 2012(14-15):163-88. French. Available from: http://www.invs.sante.fr/Publications-et-outils/BEHBulletin-epidemiologique-hebdomadaire/Archives/2012/ BEH-n-14-15-2012

21. Maurer J, Uscher-Pines L, Harris KM. Perceived seriousness of seasonal and $\mathrm{A}\left(\mathrm{H}_{1} \mathrm{~N}_{1}\right)$ influenzas, attitudes toward vaccination, and vaccine uptake among U.S. adults: Does the source of information matter? Prev Med. 2010;51(2):185-7. http://dx.doi.org/10.1016/j.ypmed.2010.05.008 PMid:20510270

22. Direction de la recherche des études de l'évaluation et des statistiques. Vaccination contre la grippe des groupes à risque. [Vaccination against influenza risk groups]. In: L'état de santé de la population en France - Suivi des objectifs annexés à la loi de santé publique - Rapport 2011. [The health status of the population in France - Objectives attached to the public health law - Report 2011]. French. Paris: DREES, 2011. Available from: http://www.drees.sante.gouv.fr/IMG/pdf/esp2011_47_ infections_obj39.pdf

23. Brien S, Kwong JC, Buckeridge DL. The determinants of 2009 pandemic $A / \mathrm{H}_{1} \mathrm{~N}_{1}$ influenza vaccination: A systematic review. Vaccine. 2012;30(7):1255-64.

http://dx.doi.org/10.1016/j.vaccine.2011.12.089

PMid:22214889

24. Vaux S, Van Cauteren D, Guthmann J-P, Le Strat Y, Vaillant V, de Valk $\mathrm{H}$, et al. Influenza vaccination coverage against seasonal and pandemic influenza and their determinants in France: a cross-sectional survey. BMC Public Health. 2011;11(30). PMid:21226919. PMCid:PMC3025842

25. Kroneman $M$, van Essen GA, John Paget W. Influenza vaccination coverage and reasons to refrain among high-risk persons in four European countries. Vaccine. 2006;24(5):6228. http://dx.doi.org/10.1016/j.vaccine.2005.08.040 PMid:16169638

26. van Essen GA, Palache AM, Forleo E, Fedson DS. Influenza vaccination in 2000: recommendations and vaccine use in 50 developed and rapidly developing countries. Vaccine. 2003;21(16):1780-5 http://dx.doi.org/10.1016/S0264-410X(03)00072-0

27. Nichol KL. Efficacy and effectiveness of influenza vaccination. Vaccine. 2008;26(Suppl 4):D17-22. http://dx.doi.org/10.1016/j.vaccine.2008.07.048 PMid:19230153

28. World Health Organization (WHO). Resolution of the World Health Assembly (WHA 56.19). Prevention and control of influenza pandemics and annual epidemics. WHA 10th plenary meeting, 2003. Geneva: WHO; 2003. Available from: http:// apps.who.int/gb/archive/pdf_files/WHA56/ea56r19.pdf

29. Blank PR, Schwenkglenks M, Szucs TD. Vaccination coverage rates in eleven European countries during two consecutive influenza seasons. J Infect. 2009;58(6):446-58 
http://dx.doi.org/10.1016/j.jinf.2009.04.001

PMid:19446340

30. Tuppin P, Samson S, Weill A, Ricordeau P, Allemand H.

Seasonal influenza vaccination coverage in France during

two influenza seasons (2007 and 2008) and during a

context of pandemic influenza $A\left(\mathrm{H}_{1} \mathrm{~N}_{1}\right)$ in 2009 . Vaccine.

2011;29(28):4632-7.

http://dx.doi.org/10.1016/j.vaccine.2011.04.064

PMid:21550376

31. Lina B, Holm MV, Szucs TD. Évolution du taux de couverture vaccinale contre la grippe en France: de 2001 à 2006.

[Evolution of influenza vaccination coverage in France from 2001 to 2006]. Med Mal Infect. 2008;38(3):125-32. French. http://dx.doi.org/10.1016/j.medmal.2007.11.014

PMid:18191520 